\title{
From CUR's Executive Officer
}

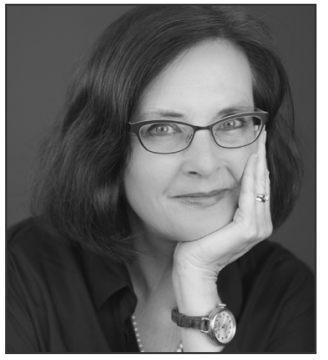

Whenever a CUR Quarterly theme issue solicitation yields a great response, those of us deeply enmeshed in CUR sit up and take notice. Judging from the diverse and thoughtful articles selected for backto-back issues, curriculum-based undergraduate research programs are proliferating rapidly, appearing earlier in students' careers and in a wider range of disciplines. Articles in this CUR Quarterly and its immediate predecessor offer graceful alternatives to the scarcity model frequently applied to the classic one-on-one faculty-mentored undergraduate research experience. As CUR Executive Board President Susan Larson noted in her guest editorial in the fall 2016 CUR Quarterly (Larson 2016), the undergraduate research apprenticeship, although high in value, simply cannot be easily scaled at most institutions. Undergraduate research embedded in curriculum has proven to be the most affordable and durable answer.

Curriculum-based undergraduate research is not a new concept, of course. Many small predominantly undergraduate institutions (PUIs) have been actively practicing this form of teaching for many years. More than two decades ago, the Fourth CUR Biennial Conference held at Hope College in 1992 focused on "The Research-Friendly Curriculum," noting disapprovingly in the call for presentations that "the term 'research' is often used as an antagonist for, rather than a synergist to, teaching" (Hope College 1991). CUR published a landmark compendium of research-supportive curricular practices (Karukstis and Elgren 2007), which remains a widely used resource. In addition to the rich array of articles in the fall and winter 2016 CUR Quarterly issues, many other articles have been published on research-based curricula in the journal that can be consulted on CUR's website, and volunteers have created a member-accessible Zotero ${ }^{\mathrm{TM}}$ bibliography of publications on research in the curriculum.

If curriculum-based undergraduate research is the answer, what is the underlying question? For many institutions, undergraduate research has emerged as a foremost strategy to both engage faculty teacher-scholars and address the pressing query: "What is a proven strategy to attract, retain, and graduate students with valued degrees and marketable skills?". A second query that follows closely behind is the following: "How can we stretch our limited resources to provide this strategy to the most students?".

So what's next, in the continuing quest to transform the undergraduate research scarcity model to one of abundance through research-based curricula, and how is CUR leading this movement? CUR's professional development workshops provide the types of peer-to-peer, faculty-driven learning that can achieve transformational change in teaching practice. In spring 2017, CUR will again be offering the "Transforming Undergraduate Research Culture and Curricula" Institute, an excellent launch pad for institutions ready to embark on systemic change to research-based curricula. A new National Science Foundation Improving Undergraduate STEM Education (IUSE) grant to the organization (DUE 1625354) titled "Integrating and Scaffolding Research into Undergraduate STEM Curricula: Probing Faculty, Student, Disciplinary, and Institutional Pathways to Transformational Change" supports a five-year project that will partner CUR with Indiana University's Center for Postsecondary Research and will work with 24 departments of biology, chemistry, physics, and psychology at 12 institutions. Participating institutions will be recruited through a national call for applications in 2016-17 and will then work intensively throughout the five-year grant period to create cohesive, research-based curricula. Two central research questions will be examined:

1. What effect do student characteristics have on student-learning experiences and outcomes in a scaffolded, inquiry-driven curriculum? and

2. How do different departmental approaches and distinct disciplinary cultures affect the integration of the components and outcomes of undergraduate research into the curriculum?

Answers to these questions should help faculty and administrators transform their institutional scenarios from those with scarce undergraduate research options to a bountiful harvest of opportunities.

\section{References}

Hope College. 1991. "Council on Undergraduate Research Fourth National Conference: The Research-Friendly Curriculum." CUR Quarterly 12(2): 10-11. Karukstis, Kerry K., and Timothy E. Elgren (Eds). 2007. Developing and
Sustaining a Research-Supportive Curriculum: A Compendium of Successful
Practices. Washington, DC: Council on Undergraduate Research.

Larson, Susan. 2016. "From CUR's President." CUR Quarterly 37(1): 2. doi: 10.18833/curq/37.1.12.

This material is based in part upon work supported by the National Science Foundation under Grant Numbers DUE 09-20275 and DUE 16-25354. Any opinions, findings, and conclusions or recommendations expressed in this material are those of the author and do not necessarily reflect the views of the National Science Foundation.

\section{Elizabeth Ambos}

Executive Officer

doi: $10.18833 /$ curq/37/2/12 